\title{
E-government 4.0 in Thailand: The role of central agencies
}

\author{
Danuvas Sagarik ${ }^{\mathrm{a}}$, Pananda Chansukree ${ }^{\mathrm{b}}$, Wonhyuk Cho ${ }^{\mathrm{c}}$ and Evan Berman ${ }^{\mathrm{c}, *}$ \\ ${ }^{\mathrm{a}}$ Graduate School of Public Administration, National Institute of Development Administration, \\ Thailand \\ ${ }^{\mathrm{b}}$ Research Center, National Institute of Development Administration, Thailand \\ ${ }^{\mathrm{c}}$ School of Government, Victoria University of Wellington, New Zealand
}

\begin{abstract}
This study discusses Thailand's digital transformation efforts with a focus on the leadership roles of its central government agencies. Thailand has progressed through various e-government policy frameworks since the 1990s, and the current military government is implementing a version '4.0' of digital transformation strategies, aiming to improve business competitiveness, citizen wellbeing, and public sector performance. Central government agencies were created or reorganized to deal with the 'silo-ization' or 'pillarization' of public organizations, as well as a need for hierarchical leadership and coordination. We discuss the challenges in maintaining reform leadership and accountability, legislation, interoperability, employee capabilities and performance management, and efforts by central agencies to address them.
\end{abstract}

Keywords: e-government, digital government, administrative reform, Thailand

\section{Introduction: Thailand 4.0, the Digital Thailand Plan, and E-Government}

Since the 1990s, digital government strategies have been among the key policy initiatives for Southeast Asian nations, used for strengthening economic development and addressing societal problems. The Association of Southeast Asian Nations (ASEAN) lists progress on e-government as a key aspect of bridging development gaps (Holliday, 2002). The Thai government particularly has been a leader in enacting ICT-enabled transformation of government; many initiatives have been developed, including the recent notion of 'e-Government 4.0'. A key feature of these efforts is strong centralized political support, including the Prime Minister's support for, and announcement of, Thailand's Digital Government Plan 2017-2022. This study discusses the institutional and governance features in Thailand's e-government transformation process, including the key policy ideas, visions, and challenges of these ICT-enabled reforms.

This study adds to the literature through highlighting the role of central agencies in these processes. Central coordination roles have received a renewed focus in the past decade following earlier New Public Management (NPM) reforms (Christensen et al., 2014). As a response to the fragmentation caused

\footnotetext{
${ }^{*}$ Corresponding author: Evan Berman, 23 Lambton Quay, Victoria University of Wellington, New Zealand. E-mail: evan. berman@vuw.ac.nz. Evab is also Adjunct Chair Professor at National Chengchi University, Taiwan.
} 
by these earlier more market-driven reforms, post-NPM approaches, such as "joined-up government" and "whole-of-government" programmes, have been adopted to build collaborative ICT environments in government by hierarchical strengthening of the center (Klievink \& Janssen, 2009; Ojo et al., 2011). Furthermore, research shows a continuing role for central agencies in leading government-wide, executivedriven public sector reforms, sometimes with support from Presidential or Prime Ministerial offices (e.g., Berman \& Prasojo, 2018). Such leadership and coordination show that Luther Gulick's principles in these matters still apply today. Thailand's case involves central agencies, dedicated to political executives' e-government agenda, leading and coordinating digital transformation, in addition to dealing with the dilemmas of adopting evolving technologies under a highly centralized structure.

Thailand's current digital government strategy is tightly connected to the country's economic and social development plans, specifically the overarching 'Thailand 4.0' strategy which targets the middleincome trap, unbalanced economic growth and inequality. The country has struggled in recent years to maintain a high level of economic performance. Today, the average growth rate is a modest 3-4 percent, compared to a booming 10 percent growth rate prior to the Asian Financial Crisis. Additionally, the economy struggles with economic volatility and loss of competitiveness in its export-orientated manufacturing due to lower-cost neighbors. Income inequality is also high, with 58 percent of the country's wealth is controlled by 1 percent of the population (Phongpaichit, 2016), and more than 80 percent of impoverished rural populations are unable to access similar social services to those found in urban areas (Asian Development Bank, 2014).

In order to address these concerns, the Thailand 4.0 strategy prioritizes increased sustainable technology- and knowledge-based economic drivers, as well as increasing access to benefits of economic growth for all income groups. The strategy includes diverse foci such as economic growth, human capital, and environmental protection under a 'Digital Thailand' plan. Thailand's e-Government 4.0 initiatives are part of this, and new technologies for the provision of public services are expected to support an overall digital transformation of Thai society, improve direct public and business services, and increase digital coordination across agencies. More broadly, they are also expected to improve public sector responses to key challenges in Thailand such as human trafficking, illegal fishing, low aviation standards, corruption, and insufficient public services.

\section{Three institutional contexts}

It is generally accepted that e-government is developed and implemented in ways that reflect institutional, socio-political, and cultural characteristics of each country (Gil-Garcia \& Sayogo, 2016; Im et al., 2014). Thailand's e-Government 4.0 efforts reflect three important contexts of Thailand. First, Thailand has a strong centralized tradition, leading from the government center in Bangkok and extending to provinces and local governments. Centralization is partly done under the rationale of leading and coordinating public sector more efficiently. As one of many consequences, local governments continue to face challenges regarding lack of staff capacity, weak back-office work, scare resources, and lack of transparency. At the same time, centralization has not always resulted in coordinated efforts by individual national ministries in digital government, as discussed below.

Second, Thailand's dominant establishment pillars - the executive, the legislative, and the judiciary - need their own justifications for legitimacy. Arrangements are fluid and dynamic, often challenging democratic principles; Thailand has experienced 19 constitutional changes in less than a century. Since 2014, Thailand is under a coup-installed military government taking control of the executive and the legislative and executive branches and, despite upcoming elections, the new 2017 constitution ensures 
that the military will continue to wield considerable influence in the legislature. The current military government centrally drafted a 20-year national strategy that is a foundation for future governments and public policy. This situation leaves the current military-led government with a strong need for citizenbased legitimacy and approval (McCargo, 2005), and the government's digitization plan and strategies include considerable emphases on public accountability and social problem resolution. ${ }^{1}$

Third, the emphasis on social integration and wellbeing (such as in current digital government plans) is also grounded in Thailand's strong Buddhist culture. Thailand is often referred to as a 'land of Buddhism' and national policy has long been explicitly formulated in a Buddhist context. While governmental policies are not always explicit in their inclusion of Buddhist values, most Thai policy makers have the Buddhist cultural tradition strongly in their mindset. Social wellbeing and citizen-centrism in e-Government 4.0 developed not just from Western experiences, but also from the Thai Buddhist values of not causing suffering to others and the concept that happiness emerges from within rather than from without. The emphasis on digital technologies empowering people to increase their 'citizen wellbeing' builds on this.

\section{Thailand's previous e-government reforms}

Thailand progressed through various ICT policy frameworks that emphasize integrated promotion of e-government with societal aspects (see Fig. 1). These different policy frameworks, and lessons learned from them, are the foundation of current e-government efforts (Varavithya \& Esichaikul, 2003).

The 1990s saw the beginning of e-government reforms in Thailand which initially were more of promise and potential than of specific strategy. The first policy framework ("IT 2000"), developed in 1996, sought to establish a coherent digital infrastructure, including initiatives such as the Government Information Network to facilitate intra- and inter-agency communication and information sharing (Thuvasethakul \& Koanantakool, 2002). E-government was developed through different individual agencies, each with different projects, software and data platforms, leading to incompatibility issues that remain today. From the mid-1990s, tangible efforts were developed to address these problems, such as the Electronic Data Interchange. The first national strategy for e-government in Thailand begun in 1996, called the "Thailand IT Policy for the $21^{\text {st }}$ Century: Social Equity and Prosperity" which set the stage for future strategies and included a societal focus.

A key priority in this national IT strategy was integrating disparate e-government systems across and between different government agencies. The National Information Technology Council and the National Electronics and Computer Technology Center provided leadership. Integration and interoperability were to be realized via these two agencies, creating a centralized coordinating authority, seeking to reduce inefficiency caused by dispersed and differentiated IT efforts across the government. From this experience, a strong commitment to a National Plan model was born, including the importance of lead agency empowerment as national-level, 'overall' change agents for central government, which remain hallmarks of current approaches.

Key tools of the Thai e-government reform model, continuing to date, are a national master strategy, a roadmap with periodic milestones, and the creation or reorganization of lead agencies with an overall

\footnotetext{
${ }^{1}$ For instance, criminal justice features heavily in this context, with human trafficking statistics placing Thailand on the Watch List by the US government. As such, one e-government initiative has involved the adoption of 'Big Data' technology for predictive policing and algorithmic criminology.
} 


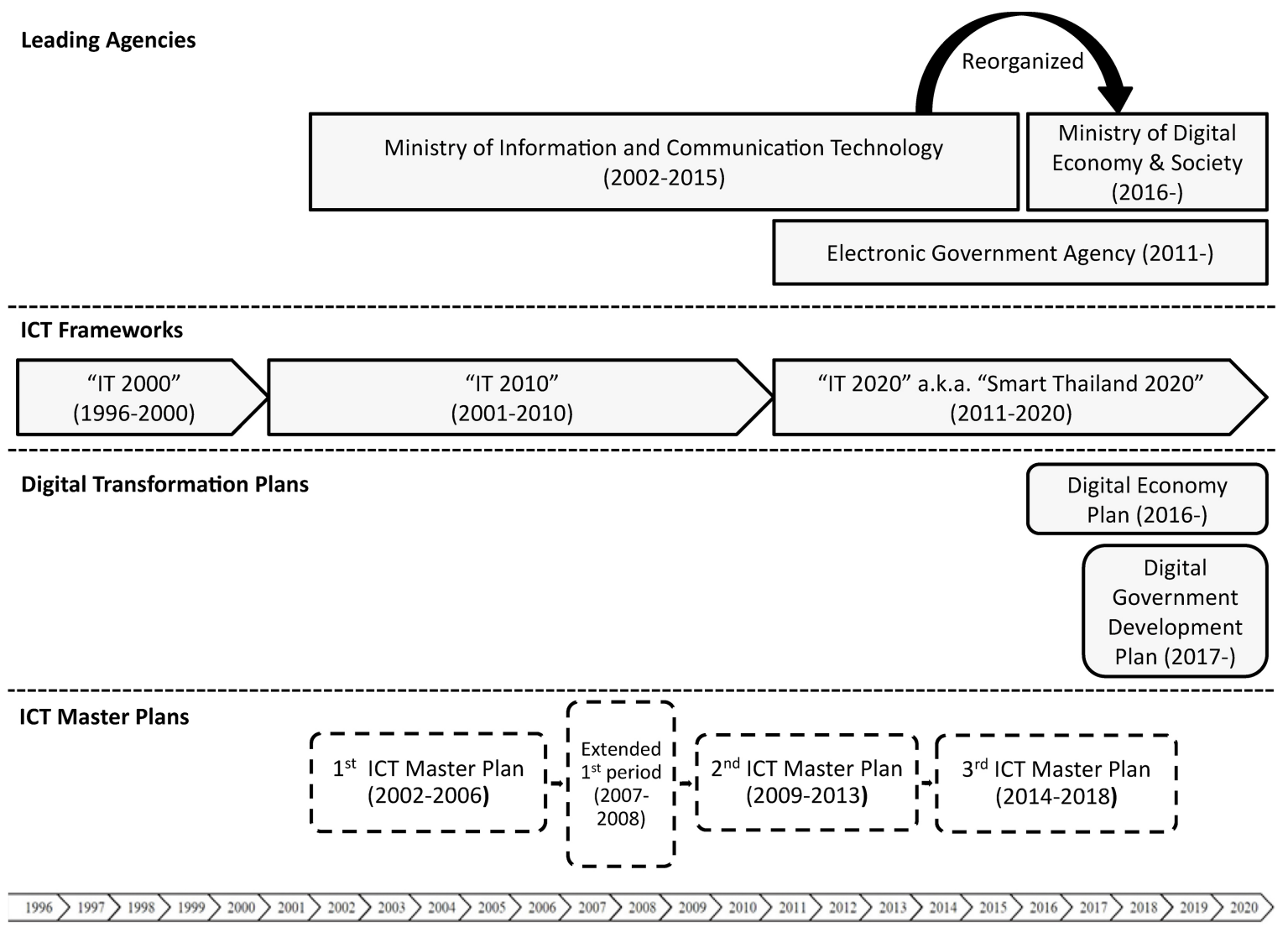

Fig. 1. Development of Thailand's ICT-enabled transformation frameworks.

centralized authority. The second framework ("IT 2010"), from 2001-2010, articulated "the 5Es Strategy' which focused on promoting e-Government, e-Industry, e-Commerce, e-Education, and e-Society. This framework emphasizes enhancing quality of life and the economy in these areas and, as a result, e-government promotion has continued to be most overt in these areas. "IT 2010" brought about a 'backbone' expansion in terms of quantity and quality improvement of new technologies throughout the country, such as expansion of broadband investment and higher number of population with ICT access and usage (Haorangsri, 2009).

The third policy framework was launched in 2011 ("IT 2020"), again with a strategic approach, but labelled as 'Smart Thailand 2020'. The vision from the Ministry of Information and Communication Technology (later renamed the Ministry of Digital Economy and Society) was for Thailand to become a 'smart nation' through foci on increasing ICT access in rural areas and those lacking access more generally via smart networks, smart government, and smart businesses. Within this, the third and current ICT master plan aims to drive Thailand towards greater digital economy. Notably, e-Government 4.0, under Thailand 4.0 model, was introduced in 2016 during the implementation of IT 2020 policy framework.

\section{Leading institutions}

The Thai government set up central public agencies for the purpose of promoting e-government and coordinating the e-government transformation of public organizations at all levels. In current efforts, 
the two key central lead agencies are the Ministry of Digital Economy and Society and the Electronic Government Agency. These central agencies provide policy-making and direct central resources towards the different levels of government institutions and to pursue consistent digital government policies across levels and across sectors via stronger instruments of central control. These central agencies also address the 'silo-ization' or 'pillarization' among public organizations in Thailand.

In 2016, the National Legislative Assembly approved replacing the old Ministry of Information and Communication Technology with a newly established Ministry of Digital Economy and Society. In addition, the Ministry of Digital Economy and Society creates e-government policies that further the digital economy and assists in restructuring government agencies to improve digital government. The Ministry of Digital Economy and Society is also responsible for supporting the private sector in developing and utilizing digital technologies and innovations. Finally, the ministry regulates digital law and cyber security, as well as strategies for engaging citizens in the policy-making processes through technology (Boonnoon, 2016).

The Ministry of Digital Economy and Society has gained strong support from the military government for realizing e-Government 4.0. It coordinates various departments and agencies such as the Digital Economy Promotion Agency, the National Statistical Office, the Meteorological Department, the Telephone Organization of Thailand, and the Communications Authority of Thailand. The number and varied nature of such actors adds to concerns regarding coordination and having adequate focus, leading to the creation in 2011, with Royal Decree, of an additional centralized strategic unit in the e-government implementation structure called the Electronic Government Agency (EGA). It operates it operates under the auspices of the Ministry of Digital Economy and Society.

Under the 'Smart Thailand 2020' plan (also known as "IT 2020"), the Thai government tasked the Electronic Government Agency with formulating consistent e-government policies across multiple levels; from the wider strategic level to small-scale actions plans, in order to maintain coherency across all sectors under the wider framework of national development of ICT. Within the public sector, horizontal and vertical coordination between agencies is seen as a major role for the Electronic Government Agency. The Electronic Government Agency provides a centralized digital platform for other government agencies to enhance efficiency and coherence, developing standards and guidelines and disseminating knowledge and best practices. The Electronic Government Agency also assists public agencies with improving public service delivery, enhancing the back-office functions, furthering access to public services for the general Thai public, and protecting the security of public e-services (Electronic Government Agency, 2016a). They are also responsible for integration of the public sector's ICT systems.

While the creation of the Electronic Government Agency was intended to enhance central coordination and responsibility, its current status under the supervision of the Ministry of Digital Economy and Society results in limited political capacity for formulating the legally-binding regulations necessary for the above. Other ministries also consider the Electronic Government Agency (due to its position under the Ministry of Digital Economy and Society) as having the same level of authority as other mid-tier ministries, which hinders central coordination of e-government as intended by the Thailand 4.0 plan. Many ministries still rely on their own digital platforms and systems for routine and strategic work. The need for central coordination persists, however, and some observers believe that the Electronic Government Agency will receive a new status under the Office of the Prime Minister, increasing its political salience, and possibly changing its name. This shows that needs for increased drive for coordination and implementation often cause a "return to the center" as governmental response. 


\section{E-government 4.0 in Thailand: Vision and strategies}

The vision embodied in the framework for the present e-government development in Thailand has four main aspects that are set forth by the Electronic Government Agency in the 3-year Digital Government Development Plan (Sekhoonthod, 2016). The first aspect is Government Integration, which involves the integration of information and operations across different agencies, towards a goal of establishing a single governmental perspective of citizens, leading to efficiency from shared services. This aspect emphasizes central coordination. The second aspect is Smart Operations, which utilizes ICT and related technologies, through Big Data and Internet of Things, to support the work of public employees. The third aspect is Citizen-Centric Services, which aims to provide services based on the needs of individual citizens. The fourth aspect is Driven Transformation, which focuses on organizational change across several dimensions, including human resources, work processes, technology, and regulation. Each of these aspects has concrete development strategies, implemented by the Electronic Government Agency. The Thai government has a vision for achieving higher levels of citizen wellbeing and business competitiveness through e-government.

\subsection{Developing capacity for supporting better government services}

In order to support specific improvements, the Electronic Government Agency is supporting the development of data technology systems that improve the efficient access and integration of data across public agencies. This includes data integration and applications in support of major issues such as resolving problems of human trafficking, illegal fishing, access to health care and education. These efforts include numerous subtasks, such as developing a centralized system with authentication and verification protocols for the connected agencies, integrating individual citizensâĂ $Z$ and government agencies' operations and business data, providing 'citizen-centric' open data platforms to provide efficient information access and, via feedback systems, proactively meeting the needs of citizens. These efforts are seen as setting examples and standards for other applications and enhancing business competitiveness.

The Electronic Government Agency is also developing training programs to improve digital literacy of public employees. This will allow public employees to address more complex problems such as human trafficking by utilizing big data and predictive analytics. Also, as the current electronic infrastructure in Thailand does not cover all public services, the Electronic Government Agency aims to improve technological infrastructure coverage with the goals of improving public service quality and increasing citizen satisfaction with government programmes.

\subsection{Elevating citizens' quality of life}

Given the current economic and cultural context of Thailand, successful e-government implementation for the country requires careful consideration of the social dimension. Quality of life (including citizen wellbeing) is a central concern for all Thai governments, including the current military government. As such, the second strategy of Electronic Government Agency has a clear focus on social development through the creation of proactive and integrated social services such as Government Smart Kiosk that provides a one-stop service portal for doing business, and GovChannel and GNews that provide easyaccess for useful information for people when dealing with public service transactions. Among these efforts is, for example, an effort using data analytics to produce better labor market research so that the supply and demand of labor can be better matched. A vertically integrated virtual labor market will be matched by the creation of career consultation services and training programs, with an aim of 
increased labor efficiency. Thailand has historically been characterized by weak citizen participation in electronic development (Sekkhoonthod, 2013) and this strategy also aims to enable and empower citizens to connect with the government in more efficient ways.

\subsection{Enhancing the capacity and competitiveness of the business sector}

The Thai government emphasizes the need to improve the business competitiveness of existing firms as well as the importance of improving ease of doing or starting a business - the government sees these as major factors contributing to the country's overall competitiveness in the globalized market. This third strategy of digital government has myriad foci; for example, it seeks higher capabilities for Thai farmers so that their production can better meet the needs of both domestic and international markets, and thereby increase their standard of living. Another example is tourism, where addressing the needs of the tourism industry is seen as a way of increasing Thailand's international reputation as a tourism destination.

This strategy aims to assist Thai entrepreneurs through an improved business environment via such things as an integrated business licensing system. Historically, regulations in Thailand are burdensome, hindering competitiveness, and the aim for digital government in the context of business competitiveness is to address these via electronic channels; for example, exporters and importers will have a 'one-stop shop' service platform for linking data to which reduces costs and time for businesses in international trade. A further aim is to enhance the competitiveness of not only large businesses, but also small and medium enterprises via integrated and proactive support such as an integrated tax system where tax data can be easily accessed and integrated across the service platform, thus reducing paper-based work, redundancies and labor costs in this area. All of this is being facilitated by improved government infrastructures in which the Electronic Government Agency plays key leadership.

\subsection{Increasing public safety and national security}

A major concern for the public sector are public safety and national security, particularly so from the perspective of the military government. Digital government is seen as an important tool. Specifically, long-standing problems for Thailand of human trafficking and undocumented immigration have put border management into the spotlight for improvement. The application of such technologies as automated border management systems increase data collection on people crossing the Thai borders, which then feeds into the integrated data network of the public service. Natural disaster and crisis management is another concern around public safety, and the digital government approach is to develop a management system driven by scenario-based simulations and integrated crisis management practices. The roles of Ministry of Digital Economy Society, as well as Electronic Government Agency, are important in addressing these issues, providing leadership for integration of the infrastructure, data, and digitalization efforts of the Thai government, especially as Thailand is now seen as being at a critical juncture in resolving these problems under the military government.

\section{Challenges in 'promise realization'}

While both the promise and the need in Thailand for e-government are large, a number of challenges are apparent. E-government transformation involves not only technology but also its interaction with people and organizations, giving rise to leadership, policy and administration challenges below. 


\subsection{Administrative challenges: Leadership, organizational culture, and staff capacity}

It is difficult to overstate administrative challenges to e-government which include ineffective leadership, insufficient employee capability, and organizational cultures that are resistant to digital transformation. In Thailand, very few Chief Information Officers have backgrounds in information management, engineering or data science, and many have spent careers across different agencies and positions, reducing their organizational knowledge and networks in specific agencies. There are also few career incentives or rewards for managers and leaders to act with a high degree of commitment to transformational ICT projects which, despite their importance, require much effort and carry significant downside risks of outcomes and change itself.

The lack of ICT experience and digital capacity (e.g. 'digital literacy') among Thai public servants has also been identified as a concern by the Office of the Civil Service Commission. Recruitment of new Thai public servants occurs, quite traditionally, via a Civil Service Exam which does not prioritize ICT proficiency, and upon employment, exposure to ICT in everyday work is still often limited. Organizations in Thailand prioritize and reward compliance with administrative routines, rather than the adoption of potentially better (though disruptive) process that might use new (and unfamiliar) ICTs. To address this, the Electronic Government Agency and the Office of the Civil Service Commission have begun a new, large-scale training program in place for increasing the digital literacy and ICT proficiency of public servants across the country. This training also embeds ICT in everyday government practice going forward, seeks to reduce ICT 'silos' and takes a consistent 'whole-of-government' approach to delivering e-Government 4.0 across the public sector.

\subsection{Legislative challenges: Rules and regulations}

Thailand currently has significant statutory ambiguities in the regulatory framework of e-government. A lack of clarity exists regarding authorities and, for example, circumstances under which information can be collected and shared (e.g., Funilkul et al., 2011). These ambiguities create or further agencies' unwillingness to share data and information across the public sector. Even minor changes in procedure are now seen to involve legal barriers that require statutory language and modification, hence, significantly hindering digital reforms.

In addition, despite the current military government strongly supporting e-Government 4.0, concerns exist that future governments may have other political priorities and interests. For example, previous Thai governments over the past decade have focused on redistributive policies that favor the poor, more so than development-orientated supply-side policies such as e-government transformation. Such policy uncertainty further contributes to timidity or inaction among public servants to the mid-term planning and actions that e-government changes require.

\subsection{Technological challenges: Infrastructure and interoperability}

While there has been significant improvement in Thailand's digital infrastructure over the past decade, a considerable lack of systems integration remains between public agencies; stand-alone technologies exist that add to agency silos in data and skills. The realization of interoperability remains as a key challenge, notwithstanding that the 'Thailand e-Government Interoperability Framework' has been under development since 2006. The siloed nature of data management in Thailand creates difficulties in accessing and utilizing data and results in a 'disconnected' or fragmented government, contrary to stated aims. The Electronic Government Agency recently established an integrated government database for 
public sector data that is more easily accessible online (www.data.go.th and www.govspending.go.th). However, this effort is only partial, as the data is still limited and not customizable for public agency users. Considerable infrastructure challenges remain for Thailand for both hardware and software compatibility and interoperability.

\subsection{Performance challenges: Monitoring and evaluation}

Currently, organizational benefits of any potential commitment to e-government reform are ill-defined, while the costs and potential liabilities of such efforts appear more certain. Consequently, public organizations are not very willing to allocate, or reallocate, scare resources to e-government projects, and particularly so when the benefits may be realized externally to that organization. Also, many Thai public agencies have yet to take inventory of their data, hence making data sharing arrangements tenuous and difficult to act on information any such agreements. As a result, many costs remain to furthering e-government reforms, including learning to use and integrate those data with other agencies. Therefore performance monitoring of ICT transformation remains a challenge as is creating feedback loops that further commitment to digital transformation in the Thai public sector. Reflecting the above, in a survey on digital readiness, public sector employees rate their organizations' technological infrastructure and data integrations at only 67 out of 100 at a national level, and only 32 out of 100 at the provincial level (Electronic Government Agency, 2017).

Added to this are challenges around the protection of privacy and security of e-government systems within the Thai public sector, and a lack of proper security controls. Funilkul et al. (2011) find that the confidentiality and privacy of information has received low attention by Thai ministries. An agency of the Ministry of Digital Economy and Society deals with computerized system security incidents in the Thai Internet community, but this unit lacks the reliable and effective technology addressing privacy and security hazards; hacking attacks remain a major issue, adding to challenges in e-government transformation.

\subsection{Societal challenges: Digital divide}

A key policy objective of e-government transformation is to provide better access for citizens in accessing government information, such as in welfare programs and social investment policies. This also opens up the possibility for the Thai government to respond faster to the needs of vulnerable populations, as well. However, a rural-urban 'digital divide' persists that challenges the realization of this goal. A 2016 national survey finds that while more than 70 percent of the Bangkok urban population uses smartphones, only 39 percent do in the more rural and less developed Northeastern region (National Statistical Office of Thailand, 2016).

The main causes of the urban/rural gap are income inequality and unequal access to high-speed internet services. The current telecommunications infrastructure in Thailand does not provide adequate and affordable high-speed internet to households in poor rural areas (Malisuwan et al., 2016; Jaroensubphayanont \& Pennee, 2016). In response, the Thai government has ordered the Telecom Organization of Thailand (one of two state-owned telecommunications enterprises) to build a national broadband network across 30,000 rural villages. This project increases the minimum broadband speed standard and fits within Thailand's five-year master plan to develop the country's physical infrastructure (Tortermvasana, 2016). 


\section{Conclusion}

In Thailand, central agencies are important in the formation and implementation of e-government strategies in the country. Thailand has progressed through various e-government policy frameworks since the 1990s and the current military government is implementing a version ' 4.0 ' of digital transformation strategies, aiming to improve business competitiveness, citizen wellbeing, and public sector performance. Central agencies have long played important roles providing leadership for visions and strategies, for providing leadership in hierarchical coordination and, in recent years, for increased horizontal integration and "de-silo-ization."

The above shows both the importance and limitations of strategies that rely so overtly on centralized lead agencies. Central agency leadership is needed to achieve vertical and horizontal reintegration in e-government initiatives. The Ministry of Digital Economy and Society and the Electronic Government Agency play important roles in policy-making and implementation. Yet, current Thailand's e-Government 4.0 plan face many challenges such as a lack of administrative capacity, a lack of regulatory clarity, technical problems of interoperability, and digital divides. Despite strong backing from the current military government, these bodies still have challenges of inadequate authority and legislation to drive change in other ministries. It seems that a need exists for yet stronger mechanisms to establish and maintain formalized lines of responsibility and accountability of the e-government reforms in Thailand.

As further measures to strengthen central control take hold, a key task is ensuring that public agencies remain pro-active and increase digital performance in their areas. The country's political leadership, bureaucrats, and experts are again discussing ways for achieving concrete results from the aforementioned ICT strategies, addressing tangible improvements in the real-life issues of citizen well-being and business competitiveness. No doubt continued efforts, with strong leadership commitment, are required to join the different and varied sectors and organizations in Thailand together to realize the promise of these strategies.

\section{Acknowledgments}

Evan Berman acknowledges funding support from NIDA, grant RC-F-RP-24 (2017-18). Evan is also Adjunt Chair Professor at National Chengchi University, Taiwan.

\section{References}

Berman, E., \& Prasojo, E. eds. (2018). Leadership and Public Sector Reform in Asian Countries. Bingley, UK: Emerald Publishers.

Boonnoon, J. (2016). Digital Economy and Society Ministry set up. The Nation (16 September 2016).

Christensen, T., Fimreite, A.L., \& Lægreid, P. (2014). Joined-up government for welfare administration reform in Norway. Public Organization Review, 14(4), 439-456.

Chutimaskul, W. (2002). E-Government Analysis and Modeling. Knowledge Management in e-Government KMGov-2002. 7 : 113-123.

Electronic Government Agency. (2017). Thailand Digital Government Readiness Survey 2017. Bangkok: Electronic Government Agency.

Electronic Government Agency. (2016a). About Us. Retrieved February 15, 2018, from https://www.ega.or.th/en/profile/874.

Electronic Government Agency. (2016b). Thailand's 3-year Digital Government Development Plan. Bangkok: Electronic Government Agency.

Funilkul, S., Chutimaskul, W., \& Chongsuphajaisiddhi, V. (2011). E-Government Information Quality: A Case Study of Thailand. In Andersen K.N., Francesconi E., Grönlund A., van Engers T.M. (eds). Electronic Government and the Information Systems Perspective. EGOVIS 2011, Toulouse, France, August 29-September 2, 2011. Proceedings (pp. 227-234). 
Gil-Garcia, J.R., \& Sayogo, D.S. (2016). Government Inter-organizational Information Sharing Initiatives: Understanding the Main Determinants of Success. Government Information Quarterly. 33(3): 572-582.

Haorangsri, A. (2009). Thailand's Experiences on National Plans and Progress Towards Building Information Society. Expert Group Meeting on Regional Cooperation Towards Building Information Society in Asia and the Pacific, 20-22 July 2009, Bangkok, Thailand

Institute for Information Technology Innovation. (2003). Report on Design and Implementation of e-Government: Institutional Capacity Building on ICT Policies in Thailand. Bangkok: Kasetsart University.

Im, T., Cho, W., Porumbescu, G., \& Park, J. (2014). Internet, Trust In Government, And Citizen Compliance. Journal of Public Administration Research and Theory, 24(3), 741-763.

Jaroensubphayanont, N., \& Pennee, N. (2016). The E-government Situation in Thai Local Government: Municipalities in Khon Kaen Province. Journal of Mekong Societies. 12: 61-76.

Klamer, A. (2017). Doing The Right Thing: A Value Based Economy. London: Ubiquity Press.

Klievink, B., \& Janssen, M. (2009). Realizing joined-up government - Dynamic capabilities and stage models for transformation. Government Information Quarterly, 26(2), 275-284.

Malisuwan, S., Kaewphanuekrungsi, W., \& Milindavanij, D. (2016). Digital divide in Thailand: Analysis and Recommendations. International Journal of Advanced Research in Engineering and Technology. 7(1): 41-46.

McCargo, D. (2005). Network Monarchy and Legitimacy Crises in Thailand. The Pacific Review. 18(4): 499-519.

Ministry of Science and Technology. (2011). Executive Summary: Thailand Information and Communication Technology Policy Framework (2011-2020). Bangkok: Ministry of Information and Communication Technology.

National Statistical Office of Thailand. (2016). The 2016 Household survey on the Use of Information and Communication technology. Bangkok: Ministry of Information and Communication Technology.

Ojo, A., Janowski, T., \& Estevez, E. (2011). Whole-of-government approach to information technology strategy management: Building a sustainable collaborative technology environment in government. Information Polity, 16(3), 243-260.

Phongpaichit, P. (2016). Inequality, Wealth and Thailand's Politics. Journal of Contemporary Asia. 46(3): 405-424.

Sekkoonthod, S. (2013). e-Government Development and New paradigm of Government Management. Retreived February, 18, 2018, from https://www.ega.or.th/Files/20120716050952.pdf.

Sekkoonthod, S. (2016). Next Generation Government. Retrieved February 20, 2018, from https://www.ega.or.th/upload/.../ file_7b3b4c6259d3914f9fa2f812f416099f.pdf.

Sukasame, N. (2004). The Development of e-Service in Thai Government. BU Academic Review. 3(1): 17-24.

Thuvasethakul, C., \& Koanantakool, T. (2002). National ICT Policy in Thailand. Africa-Asia Workshop: Promoting Coopration in information and communications technologies development. Retrieved February 10, 2018, from http://www. nectec.or.th/users/htk/publish/20020302-National-ICT-Policy-11-ppt.pdf.

Tortermvasana, K. (2016). TELEPHONE ORGANIZATION OF THAILAND will go it alone on village broadband network. Retrieved April 10, 2018, from https://www.bangkokpost.com/tech/local-news/935173/tot-will-go-it-alone-onvillage-broadband-network.

Varavithya, W., \& Esichaikul, V. (2003). The Development of Electronic Government: A Case Study of Thailand. In Traunmüller R. (eds). Electronic Government: EGOV 2003. Lecture Notes in Computer Science, Vol. 2739. Springer, Berlin, Heidelberg. 